\title{
EM BUSCAS DO TEMPO PERDIDO: ENTRE A MEMÓRIA INVOLUNTÁRIA DE BENJAMIN E OS SIGNOS DELEUZIANOS
}

\author{
Franceila de Souza Rodrigues ${ }^{1}$
}

\begin{abstract}
RESUMO
Um dos intentos literários mais ousados do século XX, Em busca do tempo perdido de Marcel Proust foi e continua sendo um dos romances mais estudados pelos filósofos da atualidade. Quais os elementos da estrutura narrativa de Em busca do tempo perdido corroboraram no reconhecimento da obra como objeto de estudo privilegiado para filósofos do século XX? Haveria uma filosofia por trás da obra de Proust? Segundo Sara Guindani, em seu artigo Proust e a Filosofia, a expressão "filosofia de Proust" pode ser interpretada de duas maneiras. Numa primeira via, "filosofia de Proust" pode aludir a referências filosóficas na obra do literato, bem como o conhecimento filosófico engendrado em consonância com a obra, um sentido que reporta a uma filosofia na qual Proust se comporta como agente. Numa segunda via, "filosofia de Proust" se refere a pensamentos filosóficos estruturados tendo como referência a obra de Proust, ou seja, a obra proustiana porta-se como objeto privilegiado na construção do pensamento filosófico de diversos pensadores no século $X X$. É em consonância com a segunda perspectiva que busco tecer este trabalho, cuja intenção principal é investigar alusões e possíveis vestígios de "Em busca do tempo perdido" na manifestação de conceitos estéticos e filosóficos da obra de Benjamin e Deleuze.
\end{abstract}

Palavras-Chaves: Experiência. Memória Involuntária. Signos.

\begin{abstract}
One of the boldest literary work of twentieth century, In Search of Lost Time by Marcel Proust was and remains one of the novels studied by philosophers of present time. Which elements of the narrative structure of In Search of Lost Time corroborated in recognition of the work as a privileged object of study by philosophers of twentieth century? Was there a philosophy behind the work of Proust? According to Sara Guindani in her article named "Proust and Philosophy", the assertion of "Proust philosophy" can be interpreted in two ways. In the first, "Proust philosophy" may allude to philosophical references in the work of Proust and philosophical knowledge written in line with the work, a sense that reports to a philosophy in which Proust acts as an agent. On the other hand, "Proust philosophy" refers to philosophical thoughts structured with reference to the work of Proust. It is in line with the second perspective that I seek to weave this essay, whose main intention is to investigate possible allusions and traces of In Search of Lost Time in the manifestation of aesthetic concepts and philosophical work of Deleuze and Benjamin.
\end{abstract}

Key Words: Experience. Involuntary memory. Signs.

\footnotetext{
1 Franceila de Souza Rodrigues é Mestranda do Programa de Pós-graduação em Filosofia da Universidade Federal de São Paulo.
} 


\section{WALTER BENJAMIN: PROUST E A EXPERIÊNCIA DA MODERNIDADE}

Walter Benjamin considera Em busca do tempo perdido um intento literário dos mais ousados e que prescinde de qualquer classificação de gênero. A Recherche é para Benjamin uma obra que conjuga em sua estrutura, além de um tratado sobre estética, também "a poesia, a memorialística e o comentário". "Já se disse, com razão, que todas as grandes obras literárias ou inauguram um gênero ou o ultrapassam, isto é, constituem casos excepcionais. Mas esta é uma das menos classificáveis"”.

Não parece excessivo afirmar que a obra de Proust constitui uma das mais importantes influências na tessitura da obra de Walter Benjamin, seja ela crítica literária ou filosófica. Como se sabe, Benjamin foi um dos tradutores da versão alemã de Em busca do tempo perdido, sendo que numa ocasião manifestou-se temeroso, pois havia se dado conta de que sua imersão na obra de Proust delineava a tessitura de sua própria obra. A admiração pela Recherche leva Walter Benjamin a considerar Proust "o narrador por excelência" do início do século XX, o narrador de um mundo em que o papel tradicional da narração como compartilhamento de um saber comum não é mais possível.

Para melhor compreensão da postura benjaminiana com relação à obra de Proust, faz-se necessário uma pequena introdução aos conceitos de experiência e vivência, dois dos mais significativos conceitos que atravessam a obra de Walter Benjamin. $O$ conceito de experiência se refere a um momento histórico específico em que, diferentemente da ideia moderna de sujeito individual, a autocompreensão do indivíduo não estava dissociada do corpo social a qual ele pertencia. O conceito de experiência está intimamente ligado à ideia de um saber compartilhado pelos pares de determinado corpo social, relacionando-se de maneira intrínseca com a caracterização da arte narrativa. A forma narrativa, segundo Benjamin, favorece a agregação de pessoas através da transmissão de valores comuns, de modo a compor um corpo social coeso. Ou seja, a narração consolida valores apreendidos pela experiência coletiva, como saber que direciona a vida individual de cada componente do grupo social: "A experiência que passa de pessoa a pessoa é a

\footnotetext{
2 BENJAMIN, 2008, p.37.
} 
fonte a que recorreram todos os narradores". "Há um caráter pedagógico e agregador na forma narrativa, que traz em sua essência uma sabedoria a ser difundida dentro do grupo a que pertence.

O conceito de vivência, por outro lado, segundo Benjamin, é o que mais se aproxima da forma de constituição do sujeito na sociedade industrial, ou seja, no período histórico compreendido entre a passagem do século XIX para o século XX, em que se verifica uma ruptura entre a autocompreensão do indivíduo e seu meio social. O conceito de vivência, dessa maneira, expressa a relação do homem imerso numa massa de desconhecidos com a qual não mantêm vínculos sociais sólidos. Conviver de maneira tão próxima com desconhecidos, como por exemplo, sentar-se num bonde ao lado de uma pessoa que se vê pela primeira vez, era uma realidade à qual os primeiros habitantes das grandes metrópoles ainda não estavam habituados. Nesse contexto, a comunicação de valores entre pares abre espaço à vivência subjetiva de homens solitários que não interagem entre si.

Benjamin considera a obra de Proust uma tentativa bem sucedida de restaurar a figura do narrador na modernidade. Nas palavras de Walter Benjamin: "Proust empreendeu a missão com extraordinária coerência, deparando-se, desde o início, com uma tarefa elementar: fazer a narração de sua própria infância"”. Na tarefa de narrar sua infância, Proust desenvolve o conceito de "memória involuntária", que segundo Benjamin, "traz as marcas da situação em que foi criado e pertence ao inventário do indivíduo multifariamente isolado". Proust, através da ideia de "memória involuntária", elabora uma espécie de reação à atrofia da experiência, na medida em que, nas palavras de Sérgio Paulo Rouanet, "recria individualmente um processo de rememoração que se tornara socialmente impossível".

Explica-se, nas sociedades tradicionais, a atividade individual de lembrar, ou seja, a memória individual estava enleada em uma espécie de memória coletiva. "Onde há experiência no sentido estrito do termo, entram em conjunção, na memória, certos conteúdos do passado individual com outros do passado coletivo" ${ }^{5}$ Com Em busca do tempo perdido Proust desenvolve uma forma moderna de narrar, ou a forma narrativa possível em tempos caracterizados pela atrofia da experiência.

\footnotetext{
3 BENJAMIN, 2008, p.198.

BENJAMIN, 2000, p. 107.

BENJAMIN, 2000, p. 107.
} 
Por meio de seu narrador, Proust abre caminho ao leitor para que a memória individual, ou seja, uma recordação particular se transforme numa via de acesso à memória coletiva. Ele consegue assim ultrapassar "os limites do individual através da dinâmica e do jogo infinito do lembrar", um movimento em que a vivência seja transmutada em experiência, ou em que se abre para a vivência a amplitude coletiva da experiência.

Um exemplo bem singelo de como se opera o deslocamento de vivência em experiência é quando o leitor do romance proustiano, através do relato do narrador, tem acesso a um acontecimento político importante na França no final do século XIX, o caso Dreyfus. Nesse movimento a memória individual consegue, pelo ato de lembrar, extrair momentos significativos que estão em consonância com a movimentação mundana dos grupos sociais descritos no romance, ou seja, são indivíduos que compartilham do mesmo momento histórico que o narrador proustiano e que, portanto, vivenciam a mesma práxis social. Esses momentos resguardos por Proust, cujos vestígios nos são tão familiares, chegam a nós como um saber universal preservado de uma totalidade imersa num tempo perdido. Para melhores esclarecimentos, cito Sérgio Paulo Rouanet ${ }^{6}$.

A importância da obra de Proust vem da tentativa de restaurar a figura do narrador numa época caracterizada pela extinção da experiência. Ele tenta realizar com meios privados o que a sociedade, com meios comunitários, oferecia antes a cada indivíduo: a possibilidade de extrair, do fundo de sua experiência, os momentos significativos do passado individual e coletivo.

O conceito de memória involuntária aparece na obra de Proust pela primeira vez em No caminho de Swann, primeiro volume de Em busca do tempo perdido. Num momento trivial da vida do narrador, quando mergulha um pedaço de bolinho, as famosas madeleines, numa xícara de chá, ele desperta para uma sensação que, a princípio, Ihe parece de uma estranha felicidade. "E de súbito a lembrança me apareceu". 7 Em um primeiro momento, Marcel, o narrador proustiano, tenta formular uma explicação desse rompante de felicidade por meio de suas observações empíricas, mas logo se dá conta de que essa estranha sensação foi engendrada, não em uma relação pura com o tempo presente, mas em um movimento de recordação do passado que involuntariamente emerge no presente. Quando se

\footnotetext{
ROUANET, 1990 , p. 50/51.

PROUST, 2003, p. 50.
} 
deleita com a madeleine molhada no chá, o narrador se recorda de que, quando criança, na casa de sua tia em Combray, provara madeleine mergulhada no chá. Nesse gesto de imergir o bolinho no chá e posteriormente saboreá-lo, os dias da infância emergem no presente, o gosto do bolinho desperta em Proust sua memória, sua infância.

E logo que reconheci o gosto do pedaço da madeleine mergulhado no chá que me dava minha tia (embora não soubesse e ainda devesse deixar para bem mais tarde a descoberta de por que essa lembrança me fazia tão feliz), logo a velha casa cinzenta que dava para a rua, onde estava o quarto dela, veio como um cenário de teatro se colar ao pequeno pavilhão, que dava para o jardim, construído pela família nos fundos (o laço truncado que era o único que recordara até então); e com a casa, a cidade, da manhã à noite e em todos os tempos, a praça para onde me mandavam antes do almoço, as ruas aonde eu ia correr, os caminhos por onde se passeava quando fazia bom tempo. E como nesse jogo em que os japoneses se divertem mergulhando numa bacia de porcelana cheia de água pequeninos pedaços de papel até então indistintos que, mal são mergulhados, se estiram, se contorcem, se colorem, se diferenciam, tornando-se flores, casas, pessoas consistentes e reconhecíveis, assim agora todas as flores do nosso jardim e as do parque do Sr. Swann, e as ninfeias do Vivonne, e a boa gente da aldeia e suas pequenas residências, e a igreja, e toda Combray e suas redondezas, tudo isso que toma forma e solidez, saiu, cidade e jardins, de minha xícara de chá. ${ }^{8}$

A tentativa de o narrador ter acesso à sua infância por meio do uso de sua inteligência, ou seja, pela memória voluntária, uma memória que não desponta de um encontro fortuito, não alcança seus objetivos. A evocação do passado, tecida em um esforço intelectivo da memória, é faltoso, carente e inútil. É o que nos sugere Sybil Douek: "Só a partir de um encontro fortuito com um objeto do passado e com a sensação que ele nos despertou e nos desperta hoje é que a memória involuntária é capaz de ressuscitar o passado, de fazê-lo reviver hoje"'. Sendo assim, para Benjamin, o conceito de memória involuntária é a tese central de Em busca do tempo perdido. Através da memória involuntária, sem o esforço da consciência, o passado vem ao encontro do presente arquitetando um movimento que rompe com o curso lógico-linear do tempo, articulando em conjunto com o imprevisível, uma crítica aos modelos totalizantes de pensamento.

A memória involuntária irrompe amparada na força do imprevisível e

\footnotetext{
PROUST, 2003, p. 50/51.

DOUEK, 2003, p. 101.
} 
alcança, tal como Proust escrevendo sua obra, um patamar criador. A Recherche é tecida num trabalho de rememoração, ou seja, tem como base, nas palavras de Benjamin, "um passado que nunca foi presente". É nesse trabalho de rememoração, de atualização no presente de sensações do passado, que a obra proustiana encontra um sentido. Proust, com sua escrita, enfrenta a ameaça do silêncio e da morte. "Mas por que motivo as imagens de Combray e de Veneza me haviam, num como noutro momento comunicado uma alegria semelhante à certeza e suficiente, sem outras provas, para me deixar indiferente à morte?". ${ }^{10}$ Segundo Proust, no momento em que o passado toca o presente, que se constitui um momento "fora do tempo", o homem consegue se libertar do aprisionamento imposto pelas determinações do tempo e da morte. É apenas pela atividade artística, pela criação literária tecida nos fios da rememoração espontânea do passado, que se alcança esse "tempo fora do tempo", um tempo desgarrado. Por fim, Jeanne Marie Gagnebin compreendeu muito bem esse movimento na obra de Proust: "Trata-se, no fundo, de lutar contra o tempo e contra a morte através da escrita-luta que só é possível se morte e tempo forem reconhecidos, e ditos, em toda a sua força de esquecimento, em todo o seu poder de aniquilamento que ameaça o próprio empreendimento de lembrar e de escrever". ${ }^{11}$

\section{DELEUZE: PROUST, OS SIGNOS E A BUSCA PELA VERDADE}

Para Deleuze, a tese central de Em busca do tempo perdido articula-se não através do conceito de memória involuntária, como defendido por Walter Benjamin, mas em torno da interpretação de signos. "A obra de Proust é baseada não na exposição da memória, mas no aprendizado dos signos". ${ }^{12}$ Deleuze defende a prevalência de quatro tipos de signos presentes na Recherche, que seriam, segundo uma disposição hierárquica, os signos mundanos, os signos do amor, os signos das impressões sensíveis e os signos da arte, este último o que mais corrobora na construção do pensamento filosófico deleuziano. Vejamos como Deleuze discorre sobre os signos na obra de Proust: "Esperamos apenas que concordem que o problema de Proust é o dos signos em geral e que os signos constituem diferentes mundos: signos mundanos vazios, signos mentirosos do amor, signos sensíveis materiais e, finalmente, os signos essenciais da arte (que transformam todos os

\footnotetext{
${ }^{10}$ PROUST,1995, p. 177.

${ }^{11}$ GAGNEBIN,2006, p.146.

${ }^{12}$ DELEUZE,2006, p.4.
} 
outros)". ${ }^{13}$ Essas quatro manifestações diferentes de signos remetem à diversidade de ambientes pelos quais Marcel, o narrador proustiano, percorre e que serão descritos ao longo das três mil páginas do romance.

Os signos mundanos, segundo Deleuze, são signos vazios, não remetem a nenhum significado ou conteúdo transcendental, esses signos ocupam o lugar de um pensamento ou uma ação. "Não se pensa, não se age, mas emitem-se signos". ${ }^{14}$ Os signos mundanos são os mais vastos e os mais tolos, ainda que se diferenciem segundo as classes sociais, são emitidos aos montes, tanto no salão dos Verdurin como no salão dos Guermantes, ou seja, tem lugar na tagarelice, seja ela burguesa ou da nobreza.

Já os signos do amor, o segundo na hierarquia deleuziana, são emitidos pelos apaixonados. "Apaixonar-se é individualizar alguém pelos signos que traz consigo ou emite. É tornar-se sensível a esses signos, apreendê-los (...)". ${ }^{15}$ Assim, estar apaixonado é tentar decifrar os signos emitidos pelo ser amado, é deixar-se envolver pela profundidade de seus mundos, nesse movimento somos levados ao encontro de experiências diversas. Os signos amorosos não são vazios, como os signos mundanos, os signos amorosos são mentirosos, estão sempre omitindo seus reais significados. Segundo Deleuze, os signos amorosos "são signos mentirosos que não podem dirigir-se a nós senão escondendo o que exprimem”, são signos dissimuladores.

Os signos sensíveis, por outro lado, não são vazios nem dissimuladores, são signos emitidos pelas impressões, ou qualidades sensíveis. "Uma qualidade sensível nos proporciona uma estranha alegria, ao mesmo tempo que nos transmite uma espécie de imperativo". ${ }^{16}$ Os signos sensíveis nos dão acesso a sensações perdidas no passado, seja ela Combray, Veneza ou uma rua de paralelepípedos. São esses signos que, por meio da memória involuntária, nos conectam com um tempo vazio, ou com a própria essência do tempo, um tempo reencontrado. No entanto, esse encontro é fugaz, já que ainda se está num tempo preso a contingências, já que no mundo dos signos sensíveis, ainda não se tem acesso à essência ideal do tempo.

Por fim temos os signos da arte, o mais importante na hierarquia do pensamento deleuziano. É pelo desvelamento dos signos da arte que temos acesso

\footnotetext{
${ }^{13}$ DELEUZE,2006, p.13.

${ }^{14}$ DELEUZE,2006, p.6.

${ }^{15}$ DELEUZE,2006, p.7.

${ }^{16}$ DELEUZE,2006, p.10.
} 
à verdade dos demais signos, porque, como Deleuze nos sugere: "Os signos da arte são os únicos imateriais ${ }^{17}$ ". Seguindo os passos da propositura deleuziana podemos dizer que cabe à arte tecer a unidade de um signo imaterial, ou seja, de conotação espiritual, com uma materialidade, esta, por sua vez, será exprimível na obra acabada. Deleuze obtém um esboço desse movimento em um exemplo recolhido da Recherche, quando a famosa sonata de Vinteuil brota do piano. Nessa movimentação do romance temos a descrição do piano, como sendo uma imagem espacial capaz de emitir um signo da arte, este, por sua vez, são "as notas surgindo como a aparência sonora de uma entidade espiritual”. Ou quando o herói de Em busca do tempo perdido decide por fim escrever sua obra, e a verdade dos diversos signos vai convergindo na tessitura da verdade essencial da obra de arte.

Pelos signos da arte é revelada a própria essência ou ideia de seu mundo. "A essência é exatamente essa unidade do signo e do sentido, tal qual é revelada na obra de arte". ${ }^{18}$ Para Deleuze, a essência revelada numa obra de arte se constrói na possibilidade aberta pelo artista de adentrar no âmago de sua subjetividade, que por sua vez, será objetivada na obra de arte. Pela arte podemos acessar diversos "mundos espirituais", por meio dos quais nos são revelados modelos diferenciados de organização da sensibilidade. Esse modo peculiar de configuração da obra de arte nos permite acessar à verdadeira essência das coisas, o que se exprime numa obra de arte não são meros signos, mas num sentido benjaminiano, a essência espiritual das coisas. Para melhor compreensão cito Sybil Douek: "A essência das coisas expressa-se através da obra de arte, diante da qual não somos livres, pois ela preexiste a nós; o verdadeiro artista é aquele que a descobre, que se submete à realidade interior e é capaz de decifrar seus signos; o escritor é um tradutor". ${ }^{19}$

Nesse sentido, mais do que interpretar signos, Em busca do tempo perdido se articula como busca pela verdade. "Na realidade, a Recherce du temps perdu é a busca pela verdade. Se ela se chama busca do tempo perdido, é apenas porque a verdade tem uma relação essencial com o tempo." 20 Os signos na obra de Proust representam, segundo Deleuze, um modo peculiar de acesso à verdade, interpretar signos é nesse sentido um caminho em busca da verdade. O primordial nesse processo é que a busca pela verdade aflore de um encontro casual, que encontre

\footnotetext{
${ }^{17}$ DELEUZE,2006, p.36.

${ }^{18}$ DELEUZE,2006, p. 38/39.

${ }^{19}$ DOUEK, 2003, p.114.

${ }^{20}$ DELEUZE,2006,p. 14.
} 
seu fundamento no involuntário, que represente um desvio à ideia clássica de que nos basta começar a pensar para pensar, e da existência a uma predisposição natural no homem para a verdade. Portanto, o entrelaçamento que Deleuze propõe entre a Recherce e uma proposição de construção filosófica do pensamento crítica aos modelos tradicionais e totalizantes, pressupõe a espontaneidade da afluência do pensamento. Nesse sentido, para Deleuze, o conhecimento se desenvolve num encontro involuntário, no acaso, tal como quando o narrador molha o bolinho no chá. "De fato, a verdade não se dá, se trai; não se comunica, se interpreta; não é voluntária, é involuntária". ${ }^{21}$

Em seu encontro com Proust, Deleuze articula, a partir de elementos de fora da filosofia, uma crítica ao modelo tradicional de formulação do pensamento fundado no rigor cartesiano e na segurança de um método capaz de assegurar uma validade universal. Articular o pensamento filosófico em bases não filosóficas, como na literatura, por exemplo, é um desvio ao controle prévio de ordenação da ideia que fortalece uma construção crítica do pensamento. Um projeto comum a filósofos tão dispares como Walter Benjamin e Gilles Deleuze, que seguem nessa longa jornada acompanhados de Proust.

${ }^{21}$ DELEUZE,2006, p. 89. 


\section{BIBLIOGRAFIA}

BENJAMIN, Walter. A imagem de Proust; Experiência e pobreza e $\mathbf{O}$ narrador. In: Obras Escolhidas. São Paulo: Brasiliense, 2008.

Sobre alguns temas em Baudelaire. In: Obras Escolhidas II. São Paulo: Brasiliense, 2000.

DELEUZE, Gilles. Proust e os signos. Rio de Janeiro: Forense Universitária, 2006.

DOUEK, Sybil Safdie. Memória e exílio. São Paulo: Escuta, 2003.

GAGNEBIN, Jeanne Marie. 0 rumor das distâncias atravessadas. In: Lembrar, Escrever, Esquecer. São Paulo: Editora 34, 2006.

GUINDANI, Sara. Proust e a Filosofia. In: Arte e Filosofia n910. Ouro Preto, 2011.

PROUST, Marcel. No caminho de Swann. Rio de Janeiro: Ediouro, 2003.

O tempo recuperado. Rio de Janeiro: Ediouro, 1995.

ROUANET, Sérgio Paulo. O Édipo e o Anjo: Itinerários freudianos em Walter Benjamin. Tempo Brasileiro: Rio de Janeiro, 1990. 